\title{
DE L'ÉTAT DE L'ARCHITECTURE EGYPTIENNE CONSIDÉRÉE DANS SONS ORIGINE, ET COMPARÉE À L'ARCHITECTURE GRECQUE. ORIGENS DA ARQUITETURA EM QUATREMÈRE DE QUINCY
}

Renata Baesso Pereira ${ }^{1}$

\section{Resumo:}

As teorias sobre a origem da Arquitetura desempenharam um papel normativo no século XVIII e envolviam especulações sobre a essência ontológica da arquitetura, a materialidade do seu desenvolvimento histórico, e sua relação com outros campos. O ensaio de Quatremère de Quincy, Mémoire sur l'architecture égyptienne de 1785, pertence a esta tradição. Em 1803, o ensaio foi revisado e publicado com o título: De l'état de l'architecture Egyptienne considérée dans sons origine, et comparée à l'architecture Grecque. Este trabalho se concentra na exegese do texto de 1803 e discute sua relação com as preceptivas que vigoravam então sobre as questões de Origem, Invenção, Caráter e, sobretudo a ênfase dada por Quatremère ao problema da Imitação, atributo da arquitetura grega que a distinguia em sua origem da arquitetura egípcia.

Palavras-chave: arquitetura, origem, imitação.

\begin{abstract}
:
The theories about the origin of Architecture played a normative role during the $18^{\text {th }}$ century and involved speculations about the ontological essence of Architecture, the materiality of its historical development, and its relation to other fields. Quatremère de Quincy's essay, Mémoire sur l'architecture égyptienne from 1785, belongs to this tradition. In 1803, the essay was reviewed and published under the title: De l'état de l'architecture Egyptienne considérée dans sons origine, et comparée à l'architecture Grecque. This paper is focused on the exegeses of the text from 1803 and discuss its relation with the preceptives which were valid by then about the issues of the Origin, Invention, Character and, above all, the emphasis given by Quatremère to the problem of Imitation, Greek's Architecture attribute, which was distinguished in its origin from the Egyptian Architecture.
\end{abstract}

Key words: architecture, origin, imitation.

\section{Quatremère de Quincy e o Prix Caylus:}

As teorias sobre a origem da arquitetura desempenharam um papel normativo no século XVIII e envolviam especulações sobre a essência ontológica da arquitetura, a materialidade do seu desenvolvimento histórico, e sua relação com outros campos. O ensaio de Antoine Chrysostome Quatremère de Quincy, Mémoire sur l'architecture égyptienne, com o qual obteve em 1785 o Prix Caylus, promovido pela Académie des Inscriptions et Belleslettres, pertence a esta tradição. ${ }^{2}$

Em 1803, Quatremère publicou uma versão revisada e ampliada deste ensaio sob o título: De l'architecture égyptienne considérée dans son origine, ses principes et son goût, et comparée sous le

\footnotetext{
${ }^{1}$ FAU-USP - Programa de Doutorado.

$2 \mathrm{O}$ sucesso obtido por Quatremère neste concurso é citado como o evento que abriu caminho para suas conquistas posteriores, sobretudo o comissionamento para escrever o Dictionnaire historique d'architecture, originalmente publicado na Encyclopédie Méthodique de Panckoucke entre 1788 e 1825.
} 
mêmes rapports à l'architecture grecque. Dissertation qui a remporté, em 1785, le prix proposé par l' Académie des Inscriptions et Belles-lettres. O presente trabalho se concentra na exegese do texto de 1803 e discute sua relação com as preceptivas que vigoravam então sobre as questões de Origem, Invenção, Caráter, Gosto e, sobretudo a ênfase dada por Quatremère ao problema da Arquitetura como arte imitativa, atributo da arquitetura grega que a distinguia em sua origem da arquitetura egípcia.

Durante o século XVIII, administrar competições desse gênero era a principal função da Académie des Inscriptions et Belles-lettres. ${ }^{3} \mathrm{O}$ acesso às competições da Académie era aberto ao público de maneira irrestrita. Os participantes poderiam exercer qualquer profissão, desde que já não fossem membros da Academia Francesa ou de uma Academia de outra nacionalidade, e deveriam atender a apenas duas condições: escrever os ensaios em francês ou latim e entregar o ensaio ao Secrétaire Perpétuel de l'Académie precisamente na data marcada. Na edição de 1785 do Prix Caylus, apenas dois ensaios foram entregues, o de Quatremère e o de um arquiteto e restaurador florentino chamado Giuseppe Del Rosso. ${ }^{4}$

Antes de proceder à exegese do texto de Quatremère de 1803, é importante contextualizar o momento em que a primeira versão foi escrita, em 1785. O tema escolhido pela Académie para o Prix Caylus versava sobre o estudo da arquitetura egípcia em geral e sua relação com a arquitetura grega. A formulação final do tema era: "Quel fut l'etat de l'Architecture chez. les Egyptiens, \& ce que les Grecs paroissent en avoir emprunté".

Apesar da preferência dos membros da Académie pela Antigüidade clássica, o Egito havia se tornado um tema importante nos questionamentos sobre a história da arte. $\mathrm{O}$ próprio Conde de Caylus, patrocinador do prêmio, e Julien-David Le Roy, dois dos mais celebrados membros da Académie, escreveram extensivamente sobre a história da arquitetura do Egito antigo. O Egito também exercia forte influência na arquitetura do século XVIII, basta olhar os trabalhos de arquitetos como Piranesi ${ }^{5}$, Claude-Nicolas Ledoux e Etienne-Louis Boullée. Este interesse histórico e estético pelo Egito era uma manifestação do papel muito maior que esta civilização representava para a Ilustração ${ }^{6}$. O

\footnotetext{
${ }^{3}$ Por serem umas das poucas atividades acadêmicas abertas ao público, tais competições desempenhavam um papel importante, atraindo novos membros e disseminando conhecimento. Além disso, as competições eram freqüentemente comemorativas, atraindo atenção e homenageando um membro da Académie, e dessa forma mantendo o prestígio dos acadêmicos em geral. O Prix Caylus foi criado em pelo Conde de Caylus em 1754 e originalmente era um prêmio que dava suporte aos estudos da antigüidade.

${ }^{4}$ Em contraste com a elegantemente ilustrada Mémoire de Quatremère, o ensaio de Del Rosso não atendia às normas da competição. A segunda parte de seu trabalho foi entregue com dois meses de atraso e embora o texto começasse em francês, a outra metade era escrita em italiano. Del Rosso havia negligenciado as duas regras da Académie e foi desclassificado. A falta de outros competidores não deprecia, contudo, a qualidade do ensaio de Quatremère, que não apenas ganhou a competição em primeira instância, mas também obteve a unanimidade do júri.O ensaio de Del Rosso foi revisado e reeditado em 1787 em Florença sob o título: "Ricerche sull'architettura egiziana e su cio che $i$ greci pare abbiano preso da quella nazione; in risposta al quesito della Accademia d'Tiscrizioni e delle Lettere di Parigi proposto per l'anno 1785" e faz parte do acervo da biblioteca Cicognara da UNICAMP.

5 "Piranesi planejou uma extensa obra sobre a introdução e o desenvolvimento das belas artes na Europa, na qual pretendia vindicar os romanos, os etruscos, bem como os egípcios em relação às pretensões dos gregos. Ele nunca foi além da introdução, mas retomou o tema da arquitetura egípcia em seu prefácio a uma série de projetos de lareiras em estilo egípcio, a maioria delas gigantescas. Apesar de nesse texto ele jamais ter se comprometido claramente em avaliar o que os etruscos haviam aprendido com os egípcios (talvez. porque Le Roy, sua bête noir, havia escrito bastante sobre o tema), ele não se furta a elogiar o mistério e a majestade dos monumentos egípcios, e o impressivo caráter sagrado dos hieróglifos".

RYKWERT, Joseph. A casa de Adão no paraíso. São Paulo: Perspectiva, 2003, p.54.

${ }^{6}$ Segundo Rykwert no século XVIII, "Para os bistoriadores da arquitetura, a arquitetura egípia era fonte de duplo encantamento: se os egipcios haviam inventado os edificios em pedra, então esta arquitetura de pedra encarnava sua sabedoria imemorial. Os etruscos, tendo aprendido com os egípcios a arte da construção em pedra e a sabedoria que esta preservou, haviam
} 
Egito fascinava a civilização ocidental desde a Antigüidade e era de tradicional importância nas formulações das histórias mundiais. As posições dos membros da Académie eram, contudo, conflituosas sobre a relação do Egito com a Grécia.

O empirismo do século XVIII não diminuiu a importância dada ao Egito na história da humanidade. Ao contrário, com uma intensidade crescente, o estudo do Egito foi tornando-se cada vez menos místico e mais científico. As pesquisas da época classificavam a civilização egípcia como mais antiga do que a dos judeus. $\mathrm{Na}$ Encyclopedie de Diderot, o Egito era caracterizado como berço da civilização, contradizendo as sagradas escrituras e o texto do Genesis.

$\mathrm{Na}$ medida que a civilização egípcia era considerada a mais antiga e, portanto, a mais próxima das sociedades primitivas, formular uma questão sobre o Egito significava formular uma questão sobre as origens e a natureza do homem.

O tema da Académie para o Prix Caylus de 1785 refletia uma nova atitude com relação ao Egito: a arquitetura egípcia era o objeto primeiramente enfocado; a arquitetura grega era uma preocupação secundária - uma ênfase desproporcional sugerida não apenas pela estrutura do texto da questão, mas também, pelo fato de que a Grécia havia sido incluída em uma última deliberação do júri. A suposição que uma relação mensurável existiu entre estas duas culturas, mesmo que não desvalorize o ideal clássico, transforma este ideal negando sua autonomia e apresentando-o como uma das muitas faces de uma estrutura histórica. Em 1785 o magnetismo exercido pelo Egito era tal que sobrepujou a independência da Antigüidade clássica. Perguntar "o que a arquitetura grega tomou de empréstimo do Egito", significava considerar este último como berço da arquitetura: o mundo clássico, embora importante como fonte para outras culturas, aparece como derivado de uma cultura anterior. O tema da Académie era, portanto, uma combinação de questionamentos das fontes bíblicas e clássicas sobre as quais as visões tradicionais da arquitetura antiga estavam baseadas.

Quatremère escreveu o ensaio de 1785 logo após o retorno de uma segunda viagem à Itália onde ele havia mergulhado no estudo da arte e da arquitetura clássicas, visitando Pompéia e Herculano, estudando os monumentos gregos em Paestum e na Sicília, e realizando medições das obras da Antigüidade. O fato de que ele não estava na Itália como ganhador do Prix de Rome, mas como um viajante independente que custeava suas despesas com uma herança de família, revela como a observação em loco das obras da Antiguidade clássica havia se tornado fundamental para qualquer um que estivesse verdadeiramente interessado em artes naquele tempo. As imagens que reproduziam os monumentos da Grécia e de Roma proliferavam, bem como imagens de monumentos de outras culturas, sobretudo do Egito, mesmo que não obedecessem a nenhum rigor de proporções e que resultassem muito mais da especulação e invenção de seus autores do que da produção de imagens a partir da observação precisa.

Apesar da indubitável importância para a carreira de Quatremère, o ensaio apresentado em 1785 à Académie é freqüentemente negligenciado, e alguns críticos afirmam que seu conteúdo ficou defasado com o advento da expedição de Napoleão ao Egito em 1798. Sem dúvida, os resultados desta expedição colocaram a arqueologia do Egito antigo em um outro patamar de conhecimento, porém o repúdio apressado ao ensaio de Quatremère, que não se constitui, absolutamente, sobre bases empíricas, negligencia outras

deixado no solo italiano exemplares mais nobres e dignos da emulação dos modernos que as recém descobertas edificações gregas podiam oferecer, visto que derivavam de cabanas de madeira."

RYKWERT, Joseph. A casa de Adão no paraíso. São Paulo: Perspectiva, 2003, p.50. 
importantes contribuições nele contidas. A análise mais detalhada do texto é decisiva para a compreensão da teoria da arquitetura de Quatremère e suas idéias sobre a origem da arquitetura.

\section{O Debate sobre as Origens da Arquitetura}

Quatremère abre o ensaio de 1803 com uma Advertência cuja análise é fundamental, pois contextualiza o momento em que sua Mémoire foi apresentada pela primeira vez à Académie, em 1785, além de justificar a reedição de um ensaio produzido a partir de fontes que naquele momento já eram consideradas defasadas.

O texto se inicia com a confirmação de que o material levantado durante a expedição de Napoleão ao Egito permitiu que os estudiosos da arte pudessem se pronunciar com muito mais certezas sobre diversas questões relativas à arte e aos monumentos daquele país. Também reconhece que os documentos anteriores à expedição, e sobre os quais baseou sua Mémoire, eram superficiais, incompletos, e incoerentes. Porém, em 1785, ao propor a questão do concurso, a Académie considerava que os materiais disponíveis então eram suficientes, não para estudos que versassem sobre os detalhes e particularidades dos monumentos do Egito, mas ao menos, para constatar o estado de sua arquitetura e deduzir os pontos de comparação que ajudariam a descobrir o que os gregos poderiam ter tomado de empréstimo dos egípcios.

Este texto ainda não havia sido publicado até 1803 e Quatremère justifica sua edição em um momento em que todos voltam seus interesses para o Egito novamente?. Não considera fora de propósito publicar um estudo baseado em fontes antigas, pois acredita que o estabelecimento de um paralelo entre estudos anteriores e novas fontes é importante para o conhecimento das artes, e finaliza sua Advertência, explicitando seus propósitos ao responder à questão da Academie:

Je répéte que ne donnaat aucune description de monuments, je n'ai dû m'engager dans aucune discussion de détails à cet égard. Je n'ai prétendu que me former, et donner une idée de l'origine, des principes et du gôut de l'Architecture égyptienne, et la comparer sous les mêmes rapports à l'Architecture grecque ${ }^{8}$.

A seqüência do texto é constituída pelo Preâmbulo, onde Quatremère discute o número, a autenticidade e a autoridade das fontes sobre as quais seu estudo está fundamentado. A possibilidade de discorrer sobre o estado da arte de uma civilização sem jamais ter conhecido seus monumentos in loco também é justificada. Inicia-se então uma operação retórica de qualificação da arquitetura grega e de desqualificação da arquitetura egípcia que vai percorrer todo o texto.

A principal dificuldade apontada, no sentido de conhecer os princípios da arquitetura egípcia é a extinção de tal civilização. Embora reconhecesse que os Gregos e os Romanos também eram povos que já haviam desaparecido, seus preceitos e exemplos faziam parte de uma tradição que não havia sido interrompida e que regulava o gosto e as preceptivas da arte na Europa Moderna.

(...) les Grecs et les Romains ont disparu depuis long-temps, mais dans les precepts et les examples conserves par une tradition non interrompue, vivans encore dans leurs ouvrages, sont devenus un object familier d'études et des

\footnotetext{
${ }^{7}$ Provavelmente Quatremère se refere ao retorno da expedição de Napoleão ao Egito e à publicação de seus resultados.
}

${ }^{8}$ QUATREMÈRE DE QUINCY. De l'architecture égyptienne. 1803. p. XI. 
connoissances communes à toute l'Europe moderne, ainsi que les regulateurs de son goût ${ }^{9}$.

A superioridade dos Gregos deve-se ao seu domínio das artes da imitação e este atributo distingue, em suas origens, a Arquitetura de Gregos e Egípcios. Tal argumento será desenvolvido ao longo de todo o ensaio, mas já no preâmbulo, Quatremère o explicita:

La grande perfection imitative de tous les arts em Grèce donne bientôt à cette nation la préeminence de goût sur toutes les autres, et cette perfection qui lui assura pour toujours le sceptre du gênie, contribua encore à l'abandon total dans lequel tomba - l'Architecture de l'Égypte. Le caprice seul, la curiosité ou la manie de nouveautés, qui n'est souvent que le retour à ce qu'il y a de plus ancién, en firent passer quelques souvenirs dans les décorations arabesques des Romains. Mais dans le fait on doit dire que cette architecture indigene ne sortit presque point des limites de son terrtoire: son gout ne put se mêler à celui des nations qui lui succédirent dans la carrière des arts et sur le theater du monde ${ }^{10}$.

As fontes - les autorités - sobre as quais apóia seu ensaio pertencem a quatro gêneros: em primeiro lugar, as descrições dos escritores gregos e romanos que embora não dominassem as noções de arquitetura propriamente ditas, representam meios importantes para comparar a fidelidade das descrições mais recentes. A autoridade das fontes antigas serve, portanto para verificar a autenticidade das fontes modernas. ${ }^{11} \mathrm{Em}$ segundo lugar estão as descrições dos monumentos do Baixo Egito, há muito conhecidas na Europa e que revelam todo o gênio da arte de construir egípcia. As obras egípcias espalhadas por toda a Europa, sobretudo aquelas que existem em Roma, como os obeliscos e estátuas de todo o gênero, carregados de hieróglifos, bem como os fragmentos de cornijas e coroamentos que podem ser vistos no Museu Britânico, em Londres constituem o terceiro gênero de fontes. Tais esculturas e partes de monumentos eram suficientes para se ter a medida do grau de imitação que as artes atingiram no Egito Antigo. Finalmente, as narrativas, descrições e desenhos dos viajantes modernos que conseguiram chegar ao Alto Egito, cujas gravuras dos monumentos podem apresentar detalhes incorretos, mas não discrepâncias nas formas principais. ${ }^{12}$

A primeira intenção de Quatremère é provar que em função da extrema simplicidade da arquitetura egípcia - que tem como principal qualidade a solidez, mas que não resulta de um sistema de proporções sofisticado - é possível formular uma idéia precisa do sistema e do gênio que presidiram sua criação apenas a partir das fontes elencadas sem conhecer in loco seus monumentos originais.

Je reponds que les autorités sur lequelles peut se fonder l'analyse de l'Architecture égyptienne, me paroissent suffisantes, surtout eu égard à la nature particulière de cette Architecture, qui, ainsi qu'on le verra, est d'une telle simplicité dans sa construction, dans ses formes et dans sa décoration, et est ensuite d'une telle uniformité que, sous ce rapport, elle ne peut se comparer à aucune autre ${ }^{13}$.

Em sua opinião, desenhos tão superficiais como aqueles disponíveis na época sobre o Egito dariam noções extremamente imprecisas se pretendessem descrever os monumentos Gregos, pois o mérito e o caráter próprio da Arquitetura Grega repousa

\footnotetext{
${ }^{9}$ QUATREMÈRE DE QUINCY. De l'architecture égyptienne. 1803. p. 1.

${ }^{10}$ QUATREMÈRE DE QUINCY. De l'architecture égyptienne. 1803. p. 2.

11 Quatremère cita obras de Cícero, Vitruvio, Heródoto entre outros.

12 Quatremère utiliza as gravuras das viagens de Norden e Pococke para ilustrar seu ensaio.

${ }^{13}$ QUATREMÈRE DE QUINCY. De l'architecture égyptienne. 1803. p. 5.
} 
sobre combinações muito delicadas que não podem ser esgotadas sem que se faça um criterioso trabalho de precisão das medidas.

Or l'on peut hasarder de dire ici d'avance, qu'il ne sauroit jamais être question dans l'Architecture égyptienne, de ces nuances légères, de ces modulations de forme, de ces combinaisons variées de parties, de rapports et d'ornemens, qui font le mérite de l'Architecture grecque, et donc les copies les plus rigoureusement exactes ne rendent encore que très infidélement l'image ${ }^{14}$.

Os melhores desenhos disponíveis até aquele momento sobre a arquiteura egípicia não apresentavam escala ou medidas, mas para Quatremère isto não invalidava sua utilização, pois um dos principais pontos que irá defender é justamente o de que esta arquitetura não possui um sistema de proporções.

Il est vrai que les meilleurs dessins que nous ayons jusqu'à ce jour des monumens
de l'Égypte, sons sans échelle et sans mesure. Totefois l'object le plus important
des mesures dans les dessins d'Architecture, est d'indiquer les rapports du tout
aux parties, et de celle-ci au tout ; c'est-à-dire, les proportions. Mais si le résultat
de l'analyse de l'Architecture égyptienne, est qu'elle n'eut point de système de
proportions, on ne voit pas que l'absence des mesures dans le dessins dont il
s'agit, puisse préjudicier beaucoup aux connoissances qu'on prétend acquéuir.

Conclui o Preâmbulo destacando que não pretende nem adivinhar e muito menos formular as regras de uma arquitetura que, muito provavelmente não tem regras. Acredita que tenha atendido às condições do Programa da Académie, na medida em que a partir das informações então existentes, pôde tornar conhecido, com o método e com a ordem que a matéria comporta, o gosto, as formas características, as principais partes, as disposições gerais, o gênio, a fisionomia, o estilo de decoração e os meios de construção da Arquitetura Egípcia.

O ensaio se compõe então de três partes. Começa com o problema da origem da arquitetura e das causas que influíram sobre o estado das artes no Egito. Na seqüência descreve os aspectos da construção, da disposição e da decoração e ao final trata dos princípios do Caráter e do Gosto desta Arquitetura, das questões essenciais que a distinguem da Arquitetura Grega e das aproximações que se constatam entre elas.

Ao tratar da questão da Origem, o problema da Invenção na Arquitetura é então abordado. Para Quatremère o fato de que os egípcios eram considerados o primeiro povo que se tinha notícia na história da humanidade não significava que fossem os inventores da Arquitetura. Tal como a linguagem, a Arquitetura não poderia ter sido inventada por um só povo em particular. Ela era necessariamente uma conseqüência universal das necessidades e atributos do homem.

Em um discurso que combinava noções de necessidade, determinantes sociais, geográficos e climáticos, Quatremère propôs três tipos arquitetônicos originais: a caverna, a tenda e a cabana que se desenvolveram, respectivamente, em sociedades de caçadores, pastores e agricultores. O desenvolvimento histórico enfatizava a linhagem genealógica de cada um dos três tipos, com especial atenção ao Caráter. Neste sentido, ele associava a excessiva solidez da arquitetura religiosa egípcia como evidência da sua derivação da caverna, por contraste, a leveza da arquitetura chinesa em madeira poderia ser comparada com a tenda; enquanto a cabana de madeira, o tipo original da arquitetura grega, ocupava uma posição intermediária.

${ }^{14}$ QUATREMÈRE DE QUINCY. De l'architecture égyptienne. 1803. p. 8. 
As máximas gerais da arte de construir, que são comuns a todas as arquiteturas, não devem ser confundidas com os princípios particulares e com os determinantes originais de cada Arquitetura. Tal abordagem evitaria o erro de alguns autores em considerar o a Arquitetura Egípcia como fonte da Arquitetura Grega apenas por terem empregado antes em seus edifícios elementos como colunas, capitéis ou cornijas. ${ }^{15}$ É preciso reconhecer então na Arquitetura Egípcia um princípio original. Se em todos os seus edifícios e em todos os seus detalhes encontra-se uma conformidade perfeita com o gosto e o gênero dos subterrâneos e cavernas, se concluirá que sua origem é muito diferente daquela dos gregos. Os empréstimos tomados pela Grécia ao Egito não poderiam ser outros que os detalhes ou acessórios estrangeiros à constituição de sua Arquitetura. A anterioridade da civilização egípcia em relação à grega é argumento de pouco valor nesta matéria, pois cada uma nasceu de um gérmen diferente.

Para Quatremère, no Egito, muitas eram as causas que se opuseram à emancipação das faculdades inventivas. A ordem política e a ação direta da religião nunca ofereceram a liberdade requerida para o desenvolvimento da faculdade imitativa. Para ele, em matéria de arte, não há invenção onde não há imitação da natureza; e esta imitação não pode ocorrer onde é proibido abandonar determinadas formas e preceitos. Na Grécia, ao contrário, circunstâncias favoráveis convergiram para emancipar as faculdades imitativas que também estavam inicialmente presas aos grilhões da rotina. Logo que foi permitido modificar os símbolos religiosos, a expressão das idéias já estava apta a libertar-se das convenções e o efeito desta liberdade foi a necessidade de comparar a obra de arte com aquela da natureza e, lentamente, se aproximar de seus modelos. Com a livre Imitação a Invenção nasceu, mas teve que trocar a escravidão da rotina pelo conhecimento das regras que o estudo aprofundado da natureza impõe e refrear então a licença da Invenção. Regras nada mais são do que observações feitas a partir da natureza. A Invenção não existe fora das regras, ela não tem o menor valor sem o parâmetro das regras para julgá-la. O estado da Arquitetura está ligado, portanto ao estado das artes da imitação que a acompanham, a saber, a pintura e, sobretudo a escultura. ${ }^{16}$

A seção final do ensaio é dedicada enfatizar a diferença original entre a Arquitetura Egípcia e a Arquitetura Grega e em apresentar algumas semelhanças de detalhes entre elas. De acordo com Quatremère, era incontestável a comunicação entre os dois povos desde tempos remotos. Como o resultado deste contato era inegável, enumerou uma série de invenções egípcias imitadas pelos gregos como por exemplo, o gosto comum entre as duas culturas pelos grandes blocos de pedra e pela construção sólida, as plantas dos templos gregos que lembravam antecedentes egípcios, algumas práticas sepulcrais egípcias que foram adotadas pelos gregos, bem como o labirinto. A lenda apresentada por Vitruvio sobre a criação do capitel Coríntio também é confrontada com a forma dos capitéis egípcios.

Quatremère apresentou extensivo material para sustentar a tese de que em razão das diferenças originais entre a caverna e a cabana, ficava mantida uma diferença essencial entre as duas arquiteturas, apesar de algumas semelhanças de ordem construtiva e técnica. A diferença requerida pela construção em madeira deu à arte grega o tempo para amadurecer e postergar a realização em materiais permanentes os esboços ainda brutos que

${ }^{15}$ QUATREMÈRE DE QUINCY. De l'arcbitecture égyptienne. 1803. p. 13.

${ }^{16}$ QUATREMÈRE DE QUINCY. De l'architecture égyptienne. 1803. p. $42-43$ 
os egípcios se apressaram em fixar e capturar em seus edifícios ${ }^{17}$. Enquanto os egípcios simplesmente arremedaram suas cavernas, os gregos transpuseram em pedra as formas de suas cabanas de madeira e através da imitação do corpo humano e da compreensão das leis da natureza, transformaram suas construções em monumentos inigualáveis. A partir da diferença entre a cabana e a caverna e da conseqüente produção de duas arquiteturas de caráter diverso, Quatremère concluiu sua resposta à questão da Académie.

Os gregos, a partir da superioridade que atingiram em outras artes de caráter imitativo, desenvolveram um sistema de proporções dentro do qual fixaram as regras de sua arte. A precisão de seu gosto deu-nos verdadeiros modelos de beleza. Os egípcios conceberam suas primeiras idéias, mas não as submeteram à reflexão e à crítica, nem as converteram em princípios. Para Quatremère, a longa lista de elementos que os gregos tomaram dos egípcios apenas provava seu grau de superação.

Il y a deux manières pour une nation d'imiter l'Architecture d'une autre. L'une qui est moins une imitation qu'une adoption, consiste à recevoir dans leur entier le système, les règles et le gout d'une Architecture. C'est que les Romains ont fait à l'égard de celle des Grecs, ou si l'on veut celle des Etrusques qui fait incontestablement la mème. C'est encore ce qui a en lieu chez les peoples modernes qui ont abandonné le gothique, et se sont approprié l'art des Grecs et des Romains.

L'autre manière d'imiter consiste à transportes seulement quelques parties d'une Architecture étrangère, à les infusee em quelque sorte dans la sienne, sans en dénaturer ni le caractere, ni le système, ni le goût. Cela s'appelle emprunter.

(...) Il est impossible de reconnaitre de la part de la Grèce, rien qui ressemble à ce qu'on pourroit appeler une adoption de l'Architecture de l'Egypte. Il faut reconnaitre au contraire, que chacune des deux nations eut une Architecture en propre, indigène, née d'um gérmen particulier, et dont les différences élémentaires n'autoient permis soit à l'une, soit à l'autre, que quelques emprunts de détails indépendants de lleur caractère essentiel.

Defensor intransigente do ideal clássico na Academie, contrários ao que considerava abusos no Ecletismo nascente, identificamos neste ensaio que pertence ao início da carreira de Quatremère, a gênese de sua teoria sobre a Arquitetura, que ele ainda desenvolveria em vários escritos posteriores.

\section{Bibliografia}

DEL ROSSO, Giuseppe. Ricerche sull'architettura egiziana e su cio che i greci pare abbiano preso da quella nazione; in risposta al quesito della Accademia d'Iscrizioni e delle Lettere di Parigi proposto per l'anno 1785. Firenze, 1787.

LAVIN, Sylvia. Quatremère de Quincy and the invention of a modern language of architecteture. Cambridge, MA: The MIT Press, 1992.

QUATREMÈRE DE QUINCY, Antoine Chrysostome. De l'état de l'Architecture Égyptienne, considérée dans son origine, ses principes et son gout, et comparée sous les mêmes rapports à l'Architecture Grecque. Paris, 1803.

Dizionario storico di architecture - le voci teoriche. A cura di FARINATI, Valeria; TEYSSOT, Georges. Venezia: Marsilio Editori, 1985.

RYKWERT, Joseph. A casa de Adão no paraíso. São Paulo: Perspectiva, 2003.

${ }^{17}$ QUATREMÈRE DE QUINCY. Prix Caylus MS, 56r. In: LAVIN, Sylvia. Quatremère de Quincy and the invention of a modern language of architecteture. Cambridge, MA: The MIT Press, 1992, p.29. 
SZAMBIEN, W. Symétrie, gout, caractère. Théorie et terminologie de l'architecture a l'age classique, 1500-1800. Paris:Picard, 1986.

YOUNÉS, Samir. The historical dictionary of architecture of Quatremère de Quincy. London: Andreas Papadakis Publisher, 1999. 